\title{
Imagens do envelhecimento: como a mídia brasileira representa a mulher de meia idade
}

\author{
Images of aging: how brazilian media represents middle-aged women \\ Maria Luiza Martins de Mendonça ${ }^{l}$ \\ (ma.luisa@terra.com.br) \\ http://dx.doi.org/10.5216/cei.v14i2.22450
}

\section{Resumo}

Se ao longo da vida mulheres e homens não são apenas diferentes, mas desiguais, pode-se supor que mulheres envelhecem diferentemente e tem de encarar as discriminações e desvantagens estruturais acumuladas ao longo da vida. Homens de meia idade possuem atributos nem sempre relacionados à sua aparência física, como maturidade, charme, poder, sucesso financeiro. Ao contrário, espera-se das mulheres que sejam jovens, bonitas e sexy. A importância de um corpo permanentemente jovem e bem modelado pode ser visto também a partir das estratégias de marketing presentes na mídia e que influencia a construção das representações, imagens e subjetividade das mulheres.

Palavras-chave: Mulheres. Envelhecimento. Mídia. Representação.

\begin{abstract}
If throughout their life women and men are that not only different but unequal, we may suppose that women age differently and have to face structural disadvantages and discrimination accumulated in their lifetime. "Middleaged" men are given attributes that are unrelated to their physical appearance, as maturity, charm, power, financial success. On the contrary, a woman is always expected to be youthful, beautiful and sexy. The importance of a permanently young and well-modeled body can be seen also as marketing strategies present in media productions which influences the construction of representations, images and women's own subjectivity.
\end{abstract}

Key-words: Women. Aging. Media. Representation.

“... o prestígio da velhice diminuiu muito, pelo descrédito da noção de experiência. A sociedade tecnocrática de hoje não crê que, como o passar dos anos, o saber se acumula, mas sim que acabe perecendo. A idade acarreta uma desqualificação. São os valores associados à juventude que são apreciados." (Simone de Beauvoir:

A velhice, 257)

\section{Mulheres, envelhecimentos}

${ }^{1}$ Doutora em Comunicação e professora na Faculdade de Comunicação da Universidade Federal de Goiás. 
Este texto resulta de um projeto de pesquisa mais amplo, intitulado "Representações do outro: $o$ olhar da mídia sobre as diversidades" e que pretende conhecer, por meio da análise de variadas produções midiáticas, conteúdos relacionados aos diferentes grupos minoritários (étnicas, de gênero, de idade, culturais, de classe) em sua articulação com as construções identitárias e subjetivas e com as práticas concretas dos indivíduos. Convém esclarecer, neste momento, que o conceito de minorias aqui utilizado não se restringe à dimensão quantitativa de determinados grupos sociais, mas de grupos sociais percebidos como "diferentes" e que são objetos, em algum momento histórico, "d'un moindre pouvoir" (GUILLAUMIN, 1981) de uma vulnerabilidade jurídico-política, social ou cultural e/ou de uma marginalização pelos sistemas hegemônicos de representação e de produção de sentido (SODRÉ, 2005, p.5). Acrescente a isso a dificuldade de se auto-representar ou de que sua representação seja feita nos seus próprios termos.

Neste caso específico, trata-se da representação da mulher e de seu processo de envelhecimento da forma como pode ser culturalmente ser percebido. Apesar das grandes transformações ocorridas nas últimas décadas, ainda podem ser encontrados resquícios de práticas coloniais e patriarcais que tratam a mulher como objeto e a colocam numa posição socialmente inferior - particularmente aquela que não possui os atributos que a colocam junto às categorias hegemônicas.

As estatísticas apontam o envelhecimento da população, tanto devido ao aumento da expectativa de vida como da diminuição das taxas de natalidade. Dados do IBGE informam sobre o aumento da longevidade no Brasil, crescimento que pode ser creditado a dois fatores complementares: diminuição da taxa de natalidade e aumento da expectativa de vida, graças ao avanço da ciência e da melhoria das condições de vida.

Essa longevidade, entretanto, é experimentada diferentemente por homens e mulheres. Estudo realizado pela demógrafa Elza Berquó aponta a existência de um desequilíbrio numérico entre homens e mulheres que tende a aumentar com o avanço da idade. Segundo a autora, esta situação resulta tanto de uma sobremortalidade masculina, quanto de uma diminuição da mortalidade feminina relacionadas à gravidez e ao parto. (BERQUÓ, 2006). Essa diferença demográfica parece incidir diretamente sobre as relações afetivas e as possibilidades de construir uma vida matrimonial estável. Não sem justificativa a autora chama de "pirâmide da solidão" o gráfico com a composição das faixas etárias no Brasil. Assim, considera-se que homens e mulheres envelhecem diferentemente, mesmo que não acrescentemos a essa 
diferença aquelas que se originam na etnia, classe econômico-social e outras. Nessa idade as pessoas se deparam com as desvantagens estruturais e discriminações acumuladas ao longo da vida.

O que significa, então, envelhecer para a mulher brasileira? Quem são essas mulheres consideradas "maduras"? Para este estudo consideram-se, aqui, mulheres com idade entre 45 e 60 $\operatorname{anos}^{2}$. Não são jovens nem tampouco podem ser chamadas idosas. Como são representadas pelos meios de comunicação? São sujeitos atuantes na vida pessoal e social? Como são mostradas suas relações com a família, com os amigos, com os afetos, com o sexo? Como se contorna a solidão? Como percebem as mudanças físicas e os apelos mediáticos para uma eterna juventude? Essas respostas podem ser buscadas, em um primeiro momento, na representação mediática e nos sentidos que elas atribuem ao velho e ao envelhecimento.

São questões pertinentes ao universo do que se convencionou chamar de "maturidade", um eufemismo para o processo de envelhecimento e que inquietam pesquisadores envolvidos com os meios de comunicação de massa que pretendem, em alguma medida, avançar um pouco sobre este universo tão próximo e ao mesmo tempo tão distante.

\section{Mídia, representação, cidadania}

Valorizar as formas de representação assume que o sentido de representar extrapola a interpretação política que o aproxima da delegação de poder, ou de estar no lugar de alguém, mas estende-se aos sistemas de atribuição de sentidos dos quais a produção da mídia é emblemática. Longe de retratar fielmente as coisas do mundo, a linguagem constrói a realidade no momento mesmo em que a nomeia. A linguagem não apenas nomeia o mundo; ela o institui (SODRÉ, 2003, p.32) e a realidade é, ela também, um efeito de discurso, tanto um produto da representação quanto seu ponto de partida. Convém lembrar que a representação não é neutra, é preciso compreendê-la tanto a partir da posição que os indivíduos ocupam em seu meio social e cultural quanto das políticas de visibilidade que a mídia adota e que são, simultaneamente, políticas de invisibilidade, posto que implicam escolhas sobre o que vai ser mostrado e como. Dito de outra forma, as idéias que circulam sobre determinados temas

\footnotetext{
${ }^{2}$ Sessenta anos representaria o início da chamada "terceira idade", categoria criada na França para enquadrar aqueles indivíduos aposentados e ainda em plena capacidade física e intelectual.
} 
não são apenas "reflexos" da realidade; são também a expressão concreta de uma relação social que deve ser inserida em um contexto histórico que a torna compreensível.

$\mathrm{Na}$ verdade, não se pode afirmar que existam limites precisos entre imagem e representação, mas ressalta a força afetiva e emocional da imagem, fazendo-a incidir sobre a constituição de identidades, a motivação para comportamentos e formação da subjetividade. Segundo Woodward (2007, p. 17)

Os discursos e os sistemas de representação constroem os lugares a partir dos quais os indivíduos podem se posicionar e a partir dos quais podem falar. Por exemplo, a narrativa das telenovelas e a semiótica da publicidade ajudam a construir certas identidades de gênero.

Assim, o termo representação social refere-se à elaboração de comportamentos e à comunicação entre indivíduos na vida cotidiana; são as diferentes representações socialmente construídas que permitem compreender e explicar a realidade, definir as identidades, orientar e justificar os comportamentos e as práticas sociais (SÁ, 1996). A mídia atua, nas sociedades contemporâneas, como elemento importante na construção da realidade social, em especial dos conteúdos simbólicos dessa realidade e da imagem que a sociedade e os diferentes grupos sociais fazem de si mesmos e dos outros. Eles apresentam e difundem idéias, imagens e representações de uma visão de mundo que indica as maneiras adequadas de comportar, de viver, a noção do correto e do impróprio, às expectativas que se podem ter, a diferença entre o possível e o utópico, enfim, atuam, ao lado de outras instâncias, como importantes construtores das subjetividades. A forma como se é mostrado na mídia, assim como a inexistência para a mídia, são indicadores relevantes para compreender como a sociedade reconhece seus diferentes membros e grupos.

A maneira como os meios de comunicação se organizaram institucionalmente no Brasil, como empresas privadas em busca de lucros, fez com que os avanços tecnológicos e o domínio de técnicas sofisticadas de produção privilegiasse a forma e os efeitos sensoriais em detrimento dos conteúdos. Esse formato tende a subordinar os conteúdos aos interesses econômicos mesmo que isso contribua para aumentar a distância que separa indivíduos, grupos e, nesse caso, gerações. Fortalece ou “naturaliza” discriminações e exclusões, simbólicas ou não. 
Portanto, a observação e a análise das imagens, das representações e dos modelos são uma das perspectivas mais importantes para compreender que ofertas simbólicas são difundidas sobre um determinado grupo e ofertadas para a sociedade em geral; nesse caso, as mulheres em particular. É, então, a partir desses pressupostos que se procedeu a avaliação sobre as representações do envelhecimento feminino na mídia brasileira contemporânea, procurando conhecer como são mostradas essas mulheres e o seu processo de envelhecimento em sua relação com a construção da cidadania. A relação entre cidadania e comunicação não se restringe ao direito ao acesso e ao uso dos meios de comunicação, mas inclui o direito de indivíduos e grupos, em suas diferenças e singularidades (sexo, idade, entre outras) serem representados de maneira coerente com a realidade que vivenciam.

Entretanto, nos discursos difundidos pela mídia tanto os destinados ao público mais amplo quanto aquele específico para mulheres, aquelas que supostamente estão acima de 50 anos são subrepresentadas e, quando o são, prevalecem as visões estereotipadas e/ou como indivíduos que compõem um nicho de mercado a ser explorado por determinados produtos e serviços destinados exatamente ao rejuvenescimento e ao retardamento da velhice.

Como no Brasil é comum denominar o país como sendo um "País jovem" (e que, por analogia os cidadãos também devem ser jovens), vive-se uma cultura que reverencia a juventude e o novo como virtudes em si mesmas, se envelhecer parece caminhar na contramão dos chamamentos midiáticos e estéticos, para a mulher a relação entre representação e construção de auto-imagem positiva pode ser muito mais difícil. Ao homem de "meia idade" são atribuídos valores desvinculados de sua imagem física, tais como maturidade, charme, poder, sucesso financeiro. Da mulher espera-se, ao contrário, que seja sempre jovem, bela e sedutora. Afinal, "no feminino a sedução se apóia essencialmente na aparência e nas estratégias de valorização estética”. (LIPOVETSKY, 2000, p. 63).

A antropóloga Mirian Goldenberg afirma ter fracassado na tentativa de constituir o grupo "Coroas", composto de mulheres de mais de 50 anos, pelo fato de "as mulheres de mais de 50 anos acharem que não são coroas ou que podem parecer mais jovens do que realmente são e o fato de não se sentirem valorizadas socialmente ao assumirem a própria idade...” (GOLDENBERG, 2008, p. 13).

Segundo a autora, na cultura brasileira é comum encontrar, a partir da disseminação de determinadas práticas relacionadas à construção de um corpo desejável e em conformidade com os padrões estéticos, a valorização de determinadas práticas que transformam o que é "natural", o corpo, 
em um corpo distintivo: o corpo. Pode-se dizer que ter "o corpo", com tudo o que ele simboliza, promove nos brasileiros uma conformidade a um estilo de vida e a um conjunto de normas de conduta, recompensada pela gratificação de pertencer a um grupo de valor superior. "O corpo surge como um símbolo que consagra e torna visíveis as diferenças entre os grupos sociais”. Dessa constatação pode-se inferir, além da valorização do corpo como um capital, um sentimento de exterioridade em relação a ele que se revela em afirmações como: “o corpo que eu quero ter” (JORDÃO, 2008), "o corpo que desejo para mim". Para "adquirir" este corpo é colocado à disposição das mulheres um imenso arsenal médico-farmacêutico-químico e de práticas físicas destinadas a educá-lo, reprimi-lo, transformá-lo, rejuvenescê-lo de maneira a (tentar) enquadrá-lo nos padrões estéticos atuais. Magreza e juventude se unem como ideais e projetos de vida.

\subsection{A mulher na mídia}

Empreendemos aqui um estudo que tenta localizar a representação (feita pela mídia) da mulher de "meia idade" em nossa sociedade com o objetivo de contribuir ao menos para: 1) oferecer subsídios para uma leitura crítica da mídia e sua estratégia de ignorar os grupos sociais excluídos do circuito da produção/consumo (entre outras exclusões possíveis); 2) a partir disso questionar essa exclusão e, mais importante, colaborar para ações que possam, efetivamente, melhorar aspectos subjetivos que contribuem para a qualidade de vida desse segmento da população.

Compreender os discursos implica, desse modo, relacioná-los criticamente ao contexto sociocultural e histórico que permitiu sua configuração atual. Este tipo de raciocínio vai permitir pensar em uma forma ou formas específicas de representar a "as imagens do envelhecimento feminino", as "maneiras adequadas e bem aceitas de envelhecer", as maneiras instituídas de envelhecer, de representar adequadamente esta fase da vida, assim como as maneiras novas de representá-las, de repensá-las e de vivê-las.

É com esse objetivo que apresentamos neste momento os primeiros resultados de um estudo que inclui publicações dirigidas ao público feminino - revistas Claudia e Marie Claire ${ }^{3}$, sites dirigidos a

\footnotetext{
${ }^{3}$ A escolha das revistas se justifica, no caso de Cláudia, por ser a mais antiga, de grande circulação e que, a julgar pelas seções fixas e encartes que publica regularmente - filhos, casa, culinária, questões relativas à vida familiar - destina-se à mulher casada, já com filhos e marido e já não tão jovem. Já a Marie Claire, uma revista mais "glamurosa", que de destina a um público mais sofisticado e cujo slogan é: “chique é ser inteligente”.Os sites foram divididos em dois tipos diferentes:
} 
mulheres e por último a análise da minissérie Cinquentinha exibida pela TV Globo em dezembro de 2009 .

As análises das revistas demonstraram que a mulher em processo de envelhecimento não existe, nem mesmo para anúncios ou reportagens que tratem do tema. Aliás, o envelhecimento também não existe, o que existe são formas e fórmulas de evitá-lo, ou, minimamente, adiá-lo. A revista Cláudia, de uma maneira que considero bastante ambígua, publica reportagens com mulheres que contribuem para alguma causa social. Neste caso, a idade pouco importa e nas duas edições pesquisadas, mostraram mulheres na faixa dos 60 anos: Priscila Siqueira, da ONG Serviço à Mulher Marginalizada (contra o tráfico de mulheres) e Inês Alberdi, diretora no Brasil para o Fundo de Desenvolvimento das Nações Unidas para as Mulheres (UNIFEM). De resto, da capa à contracapa, apenas jovens, magras e bemvestidas.

Na Marie Claire, as das entrevistas do mês, uma foi feita com Dilma Roussef com foco na saúde e no projeto político - nada de vida pessoa, compreensível; e com Regina Lundgren, herdeira das casas Pernambucanas e já vivendo seus 45 anos e sentido-se jovem e com disposição para novos afetos.

O que ser percebe a partir dessas publicações é que existem algumas dualidades que merecem registro: se por um lado os discursos apontam as possibilidades de um envelhecimento "digno" e associado ao bem-estar, essas possibilidades estão associadas a um "estilo de vida saudável” e a uma enorme gama de procedimentos cirúrgicos, técnicos, cosméticos, destinados a retardar e combater os efeitos mais visíveis do envelhecimento. Terapias de rejuvenescimento facial, cosméticos milagrosos, dietas, cabelos, exercícios são colocados na ordem das preocupações e atividades das mulheres

Por outro lado, os discursos sobre a menopausa/climatério presentes nos sites apontam para direções bastante diferentes: os sites femininos (o bolsa de mulher e o vila mulher) repetem as revistas impressas. O problema aí é não envelhecer. Mesmo que sejam mais frequentes matérias abordando diretamente o assunto, sua leitura informa que se trata de como não envelhecer.

aqueles que tratam de assuntos "de mulher" como o www.bolsademulher.com.br, e o www.vilamulher.terra.com.br e outros que abordam especificamente os temas pesquisados: mulher e envelhecimento em uma perspectiva profissional. Dentre os milhares apontados pelo sistema de busca escolhemos o site www.sobrac.org.br da SOBRAC (Sociedade brasileira do climatério) e o www.menopausa-online.com.br, este da indústria farmacêutica Bayer Schering Pharma. Na verdade, as buscas apontaram nessas duas direções, uma mais informal, dedicada ao cotidiano das mulheres e outra profissional, que "medicaliza" o envelhecimento feminino.

Comun. \& Inf, v. 14, n. 2, p. 139-153, jul./dez. 2011 
Como exemplo, podemos citar matéria intitulada "Sexualidade, menopausa e hormônios" (www.bolsademulher.com.br.) e assinada pela médica ginecologista Maria Maldonado é definitiva: "a marca do tempo é implacável: aparecem as rugas, os cabelos brancos, a pele fica mais flácida, o que para algumas pode significar se sentirem menos atraentes e belas, "sair" do mercado da conquista, enfim, entrar na menopausa". As palavras perdas, cuidados, acompanhamentos, são freqüentes ao se dirigir a mulheres nessa faixa etária. Sintomaticamente, sexo, sexual; sexualidade, beleza, ganhos (exceto de peso) têm resultados insignificantes.

Os sites da Sobrac e o menopausa-online apontam para uma medicalização do processo, como se esta fase da vida representasse simplesmente uma "alteração hormonal". Nestes casos o acompanhamento médico, associado às práticas saudáveis seria capaz de assegurar "até mesmo" a possibilidade de gozo e de uma vida sexual satisfatória, sem entrar no detalhe da estreita relação entre a satisfação na vida afetiva e sexual que lhes foi ensinada ao longo de suas existências. A associação com doenças é o ponto forte desses sites. Câncer de mama, doenças cardiovasculares, perdas ósseas e outras perdas dão o tom das matérias. O menopausa-online, embora com amplo acervo de doenças e tratamentos para pessoas nessa fase da vida, inclui informações e dicas sobre a sexualidade e a feminilidade, bem ao estilo das dicas oferecidas pelas revistas femininas: atmosfera sensual, tempo, preliminares, segurança "apesar" do corpo não tão jovem. Nesses casos o acompanhamento médico, associado às práticas saudáveis seria capaz de assegurar "até mesmo" a possibilidade de gozo e de uma vida sexual satisfatória, sem entrar no detalhe da estreita relação entre a satisfação na vida afetiva e sexual que lhes foi ensinada ao longo de suas existências.

\section{Televisão e Cinquentinha: um caso à parte?}

Em dezembro de 2009, entre os dias 8 e 18, foi ao ar, pela Rede Globo de Televisão a esperada e por duas vezes adiada minissérie Cinquentinha, de Aguinaldo Silva e escrita por Maria Elisa Berredo. Dirigida por Wolf Maya e Cláudio Boeckel, mostra a história de três (depois quatro) mulheres de mais de 50 anos em guerra para obter metade da herança de um ex-marido. O titulo parece ser referência tanto ao percentual da herança quando à idade das mulheres. O próprio Aguinaldo Silva afirma que a série é "sobre mulheres que se recusam a envelhecer" (Silva, 2009). 
Personagens principais, elas preferem a morte a revelar a idade e agem como adolescentes extemporâneas em busca talvez de uma fonte inesgotável da juventude. Verdade que a trama gira em torno da disputa por espaço na direção da falida empresa e das peripécias das iniciantes e inexperientes senhoras em negócios sérios, comuns ao universo masculino. Entretanto duas delas são mostradas como mulheres economicamente independentes, com trabalhos glamourosos (fotógrafa e atriz) que aparentemente não demandam a "expertise” necessária para comandar uma empresa.

O que chama a atenção, no entanto, mais do que as astúcias para abocanhar a herança, são as estratégias e práticas para permanecerem jovens, ou pelo menos assim parecerem. A personagem Mariana, representada por Marília Gabriela, pratica diariamente o ritual de banhar o rosto em água gelada e repetir o mantra: "eu sou jovem, eu sou jovem". A atriz Susana Vieira, representando a si mesma na personagem Lara, proíbe a jovem neta de chamá-la de avó, entre outras excentricidades destinadas a manter-se "em forma".

As relações afetivas são desimportantes, descomprometidas e se aproximam mais de fruição de prazeres efêmeros. O sexo é experimentado com rapazes mais jovens - um motorista vigoroso, um rapaz recém saído da adolescência - e percebido como algo excêntrico para mulheres de meia-idade. Os affaires, quando descobertos, causam espanto, asco e desprezo. Aliás, a liberdade sexual dessas personagens é motivo de comentários maliciosos por parte dos demais.

As atrizes mesmas fizeram significativas declarações a revistas. Marília Gabriela disse à revista Caras: "Me recuso a envelhecer e até agora tem dado certo" (Caras, 2009). Susana Vieira complementa na revista Quem: "Ninguém quer ficar velha e indesejável. E, graças a isso, sobrevivem os cirurgiões plásticos e as clínicas de estética. Todas nós seremos bonitas enquanto pudermos, financeiramente falando. Quando não tivermos mais condições financeiras, acabou.". E mais: "A imprensa tem de parar de exigir que a gente aparente a idade que tem”. (Quem, 2009).

Beauvoir propõe uma explicação para essas atitudes:

Nada nos impõe interiormente a necessidade de nos reconhecermos na imagem que nos foi fornecida pelos outros e que nos amedrontava. É por isso que é possível recusa-la verbalmente, e recusa-la também através de nosso comportamento, sendo a própria recusa uma forma de assunção. É uma opção freqüente entre certas mulheres que apostaram tudo na sua feminilidade, e para quem a idade é uma radical desqualificação. Com as roupas, a maquiagem, os gestos, elas procuram atrair alguém, mas procuram sobretudo convencer-se histericamente de que escapam à lei comum. Agarram-se à idéia 
de que 'isso só acontece aos outros' e que, para elas, que não são os outros, 'não é a mesma coisa'. (BEAUVOIR, 1990, p.361).

O que parece modernidade ou expressão de mudanças culturais que redefinem os papéis sociais e os comportamentos permitidos trilha dois caminhos distintos: uma deles é a responsabilidade pessoal pela qualidade do próprio envelhecimento, a "privatização da velhice" (DEBERT, 1999) que torna responsabilidade pessoal a administração da própria aparência e sinal de lassidão qualquer deslize ou desequilíbrio entre um hedonismo e uma permissividade nas maneiras e a constante vigilância e submissão do corpo às práticas destinadas a moldá-lo, conforma-lo às exigências das modas. Outro caminho mostra as possibilidades das mulheres maduras que apresentam características masculinas: são independentes financeira e emocionalmente, e sexualmente agem como os homens: tomam a iniciativa, não têm preconceito de idade ou posição social (em termos, o romance de Lara com o motorista não é público). Enfim, podem ser chamadas de mulheres liberadas segundo os padrões de um chauvinismo às avessas, pois a sexualidade da mulher madura é posta como ridícula, fora do comum e ao alcance das mulheres "excêntricas". As inseguranças, a incompatibilidade ente o tempo vivido e o tempo da aparência, o escasseamento dos olhares desejosos não fazem parte deste universo.

Isso porque não é comum, mesmo nas sociedades contemporâneas, em que as mulheres escolhem seus próprios parceiros, que ela tenha um status social superior ao do homem. A diferença de idade comum entre os casais e favorável ao homem, podem ser vistos mais do que "costumes", mas efeitos da dominação masculina à qual as mulheres consentem à medida que a maturidade masculina é percebida como um valor positivo. Maturidade que vem acompanhada de experiência, posição social, sucesso profissional. Assim, é legítimo pensar que o que valoriza o casal é o status do homem, não da mulher. Mais uma vez, fica patente que se homens e mulheres são desiguais, essa desigualdade permanece ou se consolida com o envelhecimento. E a minissérie Cinquentinha fez um convite irrecusável à reflexão sobre o lugar da mulher de "meia idade" na sociedade brasileira contemporânea.

\section{Algumas reflexões}

Não é tarefa fácil compreender a experiência social do envelhecimento feminino e as relações sociais concretas que condicionam as diferentes formas de envelhecer e o ponto de partida aqui foi 
tentar elaborar uma leitura critica focada especificamente em um produto midiático de alta visibilidade e, a partir daí refletir sobre as hierarquias sociais.

A representação da mulher de "meia idade" vem repleta de ambigüidades, talvez a mesma ambigüidade que visita o universo feminino: se é possível notar como regra uma sub-representação desse grupo etário, no memento em que se oferece ao público um produto que trata especificamente de mulheres nessa faixa etária, ele surge repleto de estereótipos negativos e de uma série de performances comumente condenáveis para mulheres maduras na nossa sociedade.

Além disso, as diferentes maneiras como os indivíduos e grupos são apresentados nos meios de comunicação de massa inspiram identificações, atuam como modelos de comportamentos, apontam aqueles desejáveis, mostram o que é possível, importante, descartável; enfim, dão os parâmetros e os moldes da inclusão social. O que se observou foi que os comportamentos mais evidenciados foram aqueles relacionados ao consumo e ao poder aquisitivo de cada uma. Seguindo essa lógica, a inclusão/exclusão acontece tendo como um dos balizadores a capacidade de consumo. É também pelo viés do consumo de determinados tipos de produtos e pela disseminação de determinadas práticas corporais que se pretende avaliar as cada vez mais ousadas incursões do mundo midiático na vida dessas mulheres. Das mulheres que têm poder aquisitivo para segui-las, obviamente.

Outra ambiguidade relacionada à representação do envelhecimento pode ser verificada: ao mesmo tempo em que se apresenta a possibilidade de vivenciar um envelhecimento positivo, saudável, em que a diluição das diferenças geracionais que se observa na presença de comportamentos similares - namoros, encontros, formas e locais de lazer e práticas esportivas - exclui a velhice e o envelhecimento do horizonte. Excluir não é "resolver". Essa exclusão equivale à negação: supões-se que, preferencialmente, se oferecem meios, produtos, serviços, estilos de vida destinados a ocultar, dissimular ou retardar o envelhecimento. Este procedimento idealista e dissimulador de uma realidade por si mesma indesejável pode contribuir para agravar o fato de que raramente se chega à esta fase da vida sem experimentar sentimentos de rejeição, inadequação, solidão e desvalorização social. O que se poderia chamar de "rito de passagem" para a mulher, o climatério, é banido do discurso não especializado (ou torna-se motivo de chacota).

Assim, pode-se considerar que as clivagens sociais tendem a se aprofundar nessa etapa da vida, o que leva à suposição de que também se acentua a distância entre a diferentes "velhices" 
experimentadas pelos indivíduos, determinadas pelo poder aquisitivo e sobretudo pelo gênero. Simultaneamente, o discurso da mídia é prescritivo e indica os lugares sociais que podem ou devem ser por elas ocupados legitimamente; as atividades e comportamentos que considerados apropriados. O que se poderia chamar de "rito de passagem" para a mulher, o climatério, torna-se um tema tabu e é banido do discurso não especializado e delgado à esfera médica (quando não se torna motivo de chacota).

A sociedade em que se vive atrela o modelo de sucesso à juventude e ao status social poder e enquanto isso persistir a mulher que envelhece perde seu poder de atração. Começa a sentir-se incapaz de provocar o desejo do outro e coloca em xeque o seu desejo primordial de ser amada, o que traz implicações sobre sua identidade, uma vez que o feminino se constrói como objeto de desejo do outro. Como agravante, a falta de referências para novas identificações estende o "limbo" social para o terreno da construção da identidade.

Essa supervalorização da juventude e do corpo feminino são construções históricas e culturais e nos anos recentes vem acontecendo uma mudança cultural em que a idade e a sexualidade começam a ser representadas de uma forma mais natural. Isso é mais perceptível na mídia mais sofisticada onde o retrato predominante de uma velhice assexuada está acompanhado de novas imagens de uma velhice mais "sexy", em especial em algumas peças publicitárias e no cinema. Mas, enquanto essa mudança contra estereótipos convencionais de uma velhice assexuada e desengajada, com possíveis implicações para a auto-estima e para o exercício de uma afetividade e de uma sexualidade desapegadas das regras do mercado e das normas estéticas incompatíveis com a maturidade, permanece a necessidade de transformar significados e incorporá-los à formação discursiva em que as representações não sejam tão preconceituosas nem tão descoladas da realidade vivida.

Resumindo, a importância que um corpo permanentemente jovem e bem modelado adquire incide não apenas nas representações midiáticas e na construção do imaginário, mas sobre a própria subjetividade das mulheres. Pesquisas veiculadas na grande mídia apontam tanto a insatisfação das mulheres com o seu corpo, sua aparência quanto às tentativas de modificá-lo. Insatisfação que aumenta proporcionalmente à idade. E questões relativas à aparência interferem diretamente nas relações afetivas, na auto-estima e numa presumida capacidade de atração e sedução.

Esse tratamento que os meios de comunicação dispensam ao envelhecimento feminino é questionável e problemático ao menos por duas razões. Em primeiro lugar porque a produção de 
sentidos, a própria formação discursiva, antes de ser concebida como algo dado e determinado, é vista como uma arena na qual se desenrola o embate entre diferentes forças sociais, entre discursos oriundos de diversas instâncias sociais, que faz com que a pluralidade de sentidos possíveis nos discursos socialmente produzidos se sedimentem, apontando os significados passíveis de serem legitimados e tornando inaceitáveis ou marginais tantos outros. O significado que se sedimenta é aquele que adquire o estatuto dominante, torna-se legítimo e se fixa como o sentido oficial (ORLANDI, 1996, p. 162). Ao se compreender a importância dos discursos como entidades que instituem uma realidade, a produzem e reproduzem, pois as falas individuais repetem fórmulas consensuais e refletem o ideário hegemônico. E também porque a invisibilidade, essa inexistência social de que a mídia é apenas o exemplo mais visível, coloca as mulheres que estão em na menopausa, já não podem procriar, já experimentam alterações na aparência física, enfim que estão vivenciando plenamente o "processo de envelhecimento", mas ainda não podem ser classificadas no segmento "idoso", numa espécie de "limbo" social (e talvez) subjetivo que por vergonha ou por medo lhes impede de se identificar como tais. Se não podem mais se identificar com os modelos de juventude que povoam o imaginário do que seja belo e desejável, tampouco querem se identificar como velhas ou idosas. Talvez seja essa uma das razões pelas quais a palavra menopausa faça parte do vocabulário medicalizado e pela qual o permanece a carga pejorativa do termo "coroa", que talvez justificasse o fracasso da antropóloga Mirian Goldenberg em formar um grupo de discussão ou de estudos com este nome.

Vivemos em uma sociedade em que o modelo de sucesso está atrelado ao de juventude e enquanto isso persistir a mulher que envelhece perde seu poder de atração, sente-se incapaz de provocar o desejo do outro e coloca em xeque o desejo primordial de ser amada, o que traz implicações sobre sua identidade, uma vez que o feminino se constrói como objeto de desejo do outro. Nessa lógica, velhice e obesidade são razões para criar estigmas. Como agravante, a falta de referências para novas identificações estende o "limbo" social para o terreno da construção da identidade.

Sabe-se que essa supervalorização da juventude e do corpo femininos são construções históricas e culturais, portanto transformar significados e incorporá-los à formação discursiva é o que têm feito muitos dos grupos e movimentos sociais que lutam por transformações sociais, ao colocar na agenda social temas e discussões marginais ou impensáveis e, nesse caso específico, é tarefa de todos nós.

Comun. \& Inf, v. 14, n. 2, p. 139-153, jul./dez. 2011 
Sabemos da existência de entidades que tratam das questões relativas ao idoso, como o Observatório da Longevidade e do Envelhecimento (OLHE) e do quanto tem sido feito para assegurar direitos à população idosa. Não é este o objetivo aqui. Trata-se de ações no sentido de dar visibilidade e representação dignas à mulher independentemente da idade ou da aparência física. Trata-se de vozes ainda dispersas, sem articulação com grupos ou movimentos mais significativos, mas necessários para inclusão social e simbólica dessas mulheres.

Nesse caso, trata-se de torná-las sujeitos de processos de mudanças que passam, inevitavelmente, pelos discursos dos meios de comunicação. Dessa maneira, conteúdos que expressem relevância, cidadania e equivalência entre os indivíduos, apesar de suas diferenças e singularidades, são elementos-chave para inserir no imaginário coletivo representações positivas do processo de envelhecimento, dissociando o "envelhecer bem" da capacidade de recusar ou disfarçar o processo, tanto fisicamente (não parecer velho) quanto psicologicamente (sentir-se jovem). Ainda assim, a conquista de direitos sociais e culturais não é suficiente para preencher vazios existenciais e nem para recuperar a auto-estimas abaladas por tantos anos de exclusão e discriminação por conta da aparência física e da idade.

\section{Referências}

BARROS, Mirian M. Lins (Org.). Velhice ou terceira idade. 2. ed. Rio de Janeiro: Fundação Getúlio Vargas, 2000.

BEAUVOIR, Simone de. A velhice: realidade incômoda. São Paulo: DIFEL, 1970.

BERQUÓ, Elza. Pirâmide da solidão? Disponível em: 〈www.cebrap.org.br/imagens〉.

BERTIN, Maghit (Org.). Discours audiovisuels et mutations culturelles. Paris: Harmattan, 2002.

BOBBIO, Norberto. O tempo da memória: de Senectude e outros escritos autobiográficos. Rio de Janeiro: Campus, 1997.

CARADEC, Vincent. Les deux visages de la lutte contre la discriminaion par l'âge. Mouvements, Paris, La decouverte, n.59, 2009/3.

DEBERTE, Guita G. A reinvenção da velhice. São Paulo: Fapesp/Edusp, 1999.

ELIAS, Norbert. Sobre o tempo. Rio de Janeiro: Jorge Zahar, 1998.

GUILLAUMIN, C. Femmes et théorie de la societé, remarque sur les effets théoriques de la colère des opprimées. Sociologie et societés, v. 13, n. 2, 1981. 
GOLDENBERG, Mirian. Coroas: corpo, envelhecimento, casamento e infidelidade. Rio de Janeiro: Record, 2008.

. (Org.). O corpo como capital: estudos sobre gênero, sexualidade e moda na cultura brasileira. LIPOVETISKY, Gilles. A terceira mulher: permanência e revolução do feminino. São Paulo: Cia das Letras, 2000.

SÁ, Celso P. Núcleo central das representações sociais. Petrópolis: Vozes, 1996.

SODRÉ, Muniz. Por um conceito de minoria. In: PAIVA, R. e BARBALHO, A. (Orgs.).

Comunicação e cultura das minorias. São Paulo: Paulus, 2005.

WOODWARD, K. Identidade e diferença: uma introdução teórica e conceitual. In: SILVA, Thomaz Tadeu (Org.). Identidade e diferença: a perspectiva dos estudos culturais. Petrópolis:Vozes, 2000. WOLF, Naomi. O mito da beleza: como as imagens belas são usadas contra as mulheres. Rio de Janeiro: Rocco, 1992.

CARAS, ed. 841, ano 12, n. 51.

ISTO É, ano 32, n. 2093, p.32.

\section{Outras fontes}

www.revistaquem.globo.com.br.

Www.ibge.gov.br .

Lei ${ }^{\circ} 8842$ de 4 de janeiro de 1994. 